\title{
Younger scientists feel pinch of tightening research budgets
}

Surely you've heard: money for research is harder than ever to come by, with nine in ten grant applications at the US National Institutes of Health (NIH) rejected at first pass.

The figures are discouraging, albeit not as grim as some would have you believe.

A report in September fanned scientists' resentment, announcing that in 2005 the approval rate for new R01s - grants that fund individual basic research-had fallen to $9.1 \%$, and had been dropping steadily since 2000 (Science 313, 1387-1388; 2006).

But the article only noted the success of an original submission. Researchers have three chances to submit each grant. At $17.9 \%$, the final 2005 approval rate is considerably higher than that reported in Science, but down from $25.5 \%$ in 1999. Researchers say they are feeling more of a pinch because scientific enterprise boomed during the Clinton-era budget increases.

Between 1998 and 2003, the NIH's budget doubled to an unprecedented $\$ 27$ billion. But since 2006, it has flattened out to $\$ 28.6$ billion. For fiscal year 2007, the budget is expected to take a dive for the first time in decades, a $0.23 \%$ cut from last year, which Congress is expected to finalize after the November elections.

"It's certainly true that the budget has been

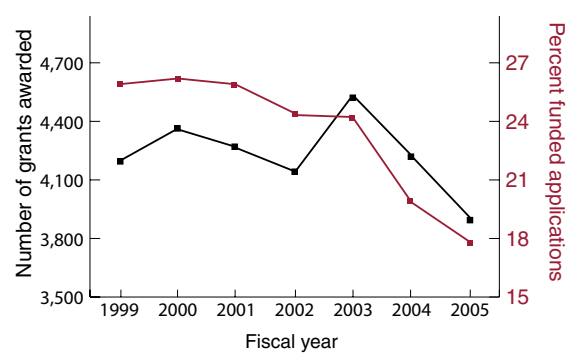

Hard times: The number of grants awarded at the National Institutes of Health has fallen since 1999.

flat and, if you consider inflation, there's actually been a decrease," says Norka Ruiz Bravo, head of the NIH's Office for Extramural Research.

Scrambling for resources, scientists are shrinking their labs, breaking up established collaborations and seeking funding elsewheresuch as with non-profits, which provide smaller grants. Some younger scientists are leaving science altogether.

"There are absolute examples of this," says Leo Furcht, director of the Marylandbased Federation of American Societies for Experimental Biology. "I can see it on a local level, as well as on a national level; I can see it with young people and older people."

Young researchers do appear to be among the hardest hit: last year, 3,894 young scientists won grants, compared with 4,521 in 2003, and the fewest since 1998. The average age at which investigators receive their first R01 has jumped from 39 in the early 1990s to 42 in 2004.

"This is killing us," says Stephen Heinemann, president of the Society for Neuroscience. "If the young people don't get the grants, all of us will get old and there'll be no science."

$\mathrm{NIH}$ officials say they are doing whatever possible to compensate. The agency has awarded 150 investigators new K99/R00 awards_-dubbed 'kangaroos'-which provide support for two years of postdoctoral work and R01-like support for the subsequent three years.

Concerned, Republican Senator Arlen Specter held a hearing in May in which NIH director Elias Zerhouni joined researchers and doctors in testifying that the budget freeze would jeopardize scientific advancement.

Congress hasn't finalized the budget, but the $\mathrm{NIH}$ is not expecting a last-minute increase.

Says H. George Mandel, chairman of the National Caucus of Basic Biomedical Science Chairs in Washington DC, who wrote the Science report. "[America's leadership in science] cannot continue without additional funding."

Alisa Opar, New York

\section{New methods suggest AIDS toll lower than estimated}

There is no doubt that the number of HIV infections worldwide is still on the rise: the toll is up to 40 million, according to UNAIDS. But are scientists using the right method to count the cases?

This year's UNAIDS estimates of the epidemic are lower than those released at the end of last year for 11 southern African countries and for China. And in August, Indian epidemiologists cast doubt on their country's high estimate of HIV cases.

Data from these new studies have broad implications for the public health response to HIV-how governments target outreach campaigns, for instance - and for bragging rights over who is doing the best job of controlling the epidemic.

The new numbers come largely from population-based surveys, in which researchers canvass communities. The surveys are more expensive and time consuming than the standard 'sentinel' surveillance, in which pregnant women at prenatal clinics and men reporting to venereal disease clinics are taken to represent general and high-risk populations.
Based on sentinel surveillance, UNAIDS estimates that India has 5.7 million HIVinfected individuals - slightly more than the government estimate of 5.2 million-earning India the unhappy distinction of being the country with the most HIV infections.

But when researchers led by Lalit Dandona, an epidemiologist at the Administrative Staff College of India, ran a population-based survey, their data suggested that the real number could be as low as 3.5 million.

Dandona's group gave HIV tests to as many people as would consent to the study in one district of Andhra Pradesh state. Based on their estimate, only 47,000 people in the district are HIV-positive, less than half of the official estimate of 113,000 people. The team then calculated an adjustment factor for this bias from their data, then applied it to data from other states, arriving at their substantially lower number for the country.

"We were very surprised," says Dandona. "Before we released this to the public, we spent a lot of time making sure we were not underestimating."

Other epidemiologists say that they're not surprised the official estimates are off.

"Many of us in the field have suspected that the standard methods of estimation have resulted in overestimates," says Willi McFarland, director of HIV/AIDS Statistics and Epidemiology for the San Francisco Department of Public Health.

Sentinel surveys are great for tracking trends - to pinpoint sites where infections are rising, for instance-but they're not ideal for predicting absolute numbers, he says.

One explanation for India's overestimate may be that the poor are more likely to be infected than are the wealthy, and a higher proportion of the poor go to public clinics.

Officials are still mulling over the implications of the study. UNAIDS expert Peter Ghys says population-based surveys in other states indicate that the birth clinic HIV rates accurately reflect HIV infections in the general population.

India's National AIDS Control Organisation adds that it is reviewing the methods but is not likely to conduct large population-based surveys because they are too expensive.

Erika Check, San Francisco 